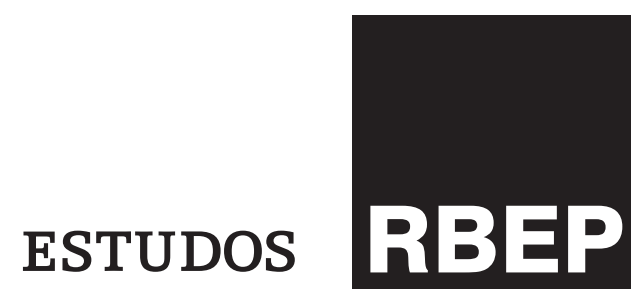

\title{
Por uma didática mediada pela sensibilidade: no caminho de um ser professor
}

\author{
Maria Candida Varone de Morais Capecchi ${ }^{\mathrm{I}}$, II \\ Vivilí Maria Silva Gomes ${ }^{\mathrm{III}, \text { IV }}$ \\ Marissel Marques ${ }^{\mathrm{V}, \mathrm{vI}}$
}

http://dx.doi.org/10.24109/2176-6681.rbep.98i250.2895

\section{Resumo}

Este artigo analisa aulas da componente curricular didática, comum a cursos de licenciatura de uma universidade federal, como forma de investigar ações formativas que vêm sendo realizadas pelas autoras em aulas de graduação. A componente curricular aqui analisada visa problematizar as concepções dos estudantes acerca do ser professor por meio de discussões em sala de aula fundamentadas em teóricos da área, de modo a despertar nos discentes uma postura professoral que, além do saber e do fazer docentes, intelectualmente apreendidos, seja impregnada por elementos sensíveis, ampliando seus repertórios de representações para atuação profissional. Busca-se, assim, promover uma discussão sobre caminhos possíveis na formação inicial de professores que ultrapassem a ideia de profissional técnico-reflexivo-crítico e contemplem a sensibilidade como parte do processo. Os dados analisados mostraram que as interações ocorridas em aula, pautadas por elementos artísticos, levaram ao desenvolvimento de um respeito mútuo entre os participantes e promoveram uma educação para 
a autonomia. Foi notoriamente evidenciado um rompimento com alguns dispositivos de controle dos corpos, que vinham imbuídos em uma atitude inicialmente passiva dos estudantes diante da relação pedagógica. Dessa forma, foi possível identificar meios para fomentar nos futuros professores o vislumbrar de novas possibilidades de interpretação e intervenção nos processos educativos.

Palavras-chave: formação inicial de professor; didática; professor reflexivo.

\section{Abstract \\ For a didactics mediated by sensitivity: on the way to become a teacher}

This paper analyzes didactics lessons, standard for teacher-training courses in a federal university, as a tool to investigate training activities performed by the authors in higher education classes. The curricular component here analyzed aims to problematize student's conceptions about teaching via in-class discussions based on theorists in the field. Therefore, it seeks to stimulate in students a teacher behavior that, beyond the knowledges related to teaching, intellectually taught, is steeped in sensitivity, broadening their repertoire of concepts to be employed in their professional performance. Thus, it intends to initiate a debate on possible paths to follow in the initial education of teachers surpassing the idea of a technical-reflective-critical professional and contemplating sensitivity as part of the process. Analyzed data shows that in-class interactions, supported by artistic elements, led to mutual respect among participants and promoted an education for autonomy. Notably, there was a departure from some systems of control over bodies that permeated the initially passive demeanor of the students in face of pedagogical interactions. Ergo, it was possible to identify means to instigate in future teachers an urge for new possibilities to interpret and intervene in the educational procedures.

Keywords: initial education of teachers; didactics; reflective teacher.

\section{Introdução}

Ao longo de sua formação, o licenciando entra em contato com saberes específicos de sua área de conhecimento e com saberes pedagógicos. Além disso, entre os saberes inerentes ao ser professor, podem-se destacar aqueles adquiridos no exercício da profissão. São vários os estudos que se referem a esses saberes, assim como àqueles construídos ao longo de 
toda a trajetória percorrida pelos professores ainda como alunos e ao peso que representam no exercício da profissão. Considerando a complexidade do trabalho pedagógico e a necessidade de integração dos diversos saberes que constituem a profissão docente - os quais estão envolvidos na coordenação de ações em sala de aula e também além desses limites -, torna-se premente romper com o isolamento docente por meio de uma perspectiva interdisciplinar, propiciando o envolvimento com múltiplos olhares referenciais que atuem no sentido do aprender com o diferente, de compartilhar o similar e preservar o que lhe é próprio: um processo de (res)significar o singular a partir, e por meio, do plural. Esse caminho, contido na agenda proposta por Candau (apud André; Cruz, 2012), tem sido trilhado pelas autoras deste artigo, ao se dedicarem à docência da didática nos cursos de licenciatura nos quais atuam.

Neste texto, é apresentado o relato de um bloco de aulas da componente curricular didática, comum a cinco cursos de licenciatura de uma universidade, como forma de exemplificar ações formativas que vêm sendo realizadas pelas autoras em suas aulas de graduação. Partindo de uma concepção de professor como profissional crítico-reflexivo (Freire, 1996; Contreras, 2012), essa componente curricular visa, principalmente, à problematização das concepções dos estudantes acerca do ser professor, concepções essas construídas ao longo de suas trajetórias como alunos e de suas vivências em programas de inserção à docência existentes na universidade, como o Programa Institucional de Bolsa de Iniciação à Docência (Pibid). Para fomentar as discussões em sala de aula, são realizadas leituras de textos de referência sobre os temas: trajetória histórica da didática; natureza do trabalho docente e profissionalização; relação pedagógica; teorias sobre ensino e aprendizagem; recursos e modalidades didáticas e avaliação. Essas leituras são acompanhadas de atividades envolvendo formas de expressão para além do verbal, com base em uma concepção de formação de professores pautada no desenvolvimento da sensibilidade, de modo a ultrapassar o tratamento estritamente técnico da relação pedagógica. Como pesquisadoras, essa concepção nos leva a proposições que objetivam despertar nos discentes uma postura professoral que, além do saber e do fazer docentes intelectualmente apreendidos, seja impregnada por elementos sensíveis, de maneira a ampliar seus repertórios de representações para a atuação profissional. Busca-se, assim, apresentar à comunidade de pesquisa essa iniciativa a fim de proporcionar uma discussão sobre caminhos possíveis na formação inicial de professores.

\section{A formação inicial de professores: algumas perspectivas}

Uma formação de professores que procura evidenciar as escolhas, mais do que o fornecimento de instrumentos prontos, visa promover nos envolvidos uma atitude reflexiva, de tomada de consciência de seus saberes e valores em relação à profissão. Nóvoa (1992, p. 16) afirma que a identidade do professor "é um lugar de lutas e conflitos, é um lugar de construção de maneiras de ser e de estar". A construção da identidade necessita de tempo 
para acomodar inovações, assimilar mudanças e (re)pensar a prática, num processo de autoconsciência sobre ações docentes e motivações para essas ações. Para o professor, porém, muitas vezes cercado de uma imagem de especialista infalível (Contreras, 2012), o caráter de inacabamento que se encontra por trás dessa ideia nem sempre é bem aceito.

Durante muito tempo, a formação de professores foi baseada no modelo denominado racionalidade técnica (Schön, 2000), em que o contato com a prática da profissão era realizado apenas nos anos finais de formação, após toda uma carga de teorias pedagógicas e de conteúdos específicos de determinada área de conhecimento. A racionalidade técnica tem como principal característica definir a prática do profissional da educação como instrumental, no sentido de aplicar certos conhecimentos teóricos e práticos baseados nos procedimentos de pesquisa científica: "é instrumental porque supõe a aplicação de técnicas e procedimentos que se justificam por sua capacidade para conseguir os efeitos ou resultados desejados" (Schön apud Contreras, 2012, p. 101). Assim sendo, traz em si uma ideia de neutralidade do professor diante de sua prática, que é constituída pela utilização racional das ferramentas a ele disponibilizadas nos cursos de formação, de modo a otimizar recursos e tempo para alcançar os resultados esperados.

Essa concepção vem sendo criticada há anos por pesquisadores da área de educação, que reconhecem cada vez mais o importante papel tanto da trajetória escolar do professor como aluno e de sua prática profissional quanto das dimensões de seu saber profissional. Dessa forma, há a valorização dos saberes dos professores que são constituídos durante sua atuação nas instituições de ensino e a necessidade de reconhecimento e potencialização dessa faceta da profissão (Tardif, 2014; Perrenoud, 1999), assim como de seus conhecimentos tácitos estabelecidos em toda a sua trajetória educacional.

É importante proporcionar, tanto na formação inicial quanto na continuada, oportunidades para que futuros professores e professores em serviço reflitam e expressem sobre o sentido que o ser professor tem em suas vidas, conscientizando-se de seus saberes, valores, angústias e anseios (Pimenta, 2005). Alarcão (2011) afirma que a concepção de professor reflexivo está pautada "na consciência da capacidade de pensamento e reflexão que caracteriza o ser humano como criativo e não como mero reprodutor de ideias e práticas que lhe são exteriores" (Alarcão, 2011, p. 44).

A criatividade e a consciência são elementos indispensáveis para o desenvolvimento da personalidade e da capacitação para autonomia, discernimento e responsabilidade pessoal, portanto, fundamentais na construção do conhecimento educacional. Para isso, a educação deve considerar todas as potencialidades do indivíduo: memória, raciocínio, sentido estético, capacidades físicas, aptidão para comunicar-se. Schön (2000) chama o domínio desse complexo conjunto de saberes de talento artístico.

Compreender a educação como uma ação social, cultural e política implica reconhecer a autonomia e a emancipação como requisitos necessários para uma consciência do mundo e uma consciência de si, inscritas também no âmbito ético. A formação de professores deve 
proporcionar condições para que licenciandos e profissionais reflitam sobre seus saberes e os significados destes para si.

Pensar acerca do significado da profissão para si e de todas as suas representações possibilita a licenciandos e professores a realização de escolhas conscientes, assumindo uma postura de autoria de seu processo profissional. Esse é o princípio que norteia as aulas aqui descritas, inspiradas em alguns pressupostos básicos de Paulo Freire para a caracterização de um educador. Em seu livro Pedagogia da Autonomia: saberes necessários à prática educativa, Freire (1996) destaca que o professor, denominado por ele progressista, que visa ao desenvolvimento da autonomia de seus educandos, reconhece que não há docência sem discência, que ensinar não é transferir conhecimentos e que é uma especificidade humana.

Reconhecer que não há docência sem discência implica reconhecer que o ensino-aprendizagem intencional só acontece quando se estabelece uma relação pedagógica entre professor, alunos e conhecimentos. Para que essa relação de fato aconteça, é necessária a constituição de um campo intensivo em que todos os envolvidos estejam em conexão, promovendo a emancipação do educador e do educando e potencializando ambos para a geração de novos conhecimentos. Nesse sentido, o estabelecimento da relação pedagógica professor-alunos-conhecimento deve proporcionar um encontro no qual diferentes indivíduos possam se expressar para ampliar suas formas de pensar, rompendo com a mera reprodução de saberes.

É importante destacar algumas ideias que Freire (1996) defende de forma recorrente em seu livro, a noção de inacabamento do ser humano e a importância de que se reconheça condicionado, mas não determinado. Cada ser humano se compõe com forças históricas que o condicionam, porém, não o determinam, uma vez que é possível construir outras composições. E preciso criar condições para que novas composições sejam vislumbradas e experimentadas. Para tanto, mais uma vez, mostra-se necessária a criação de espaços de expressão de ideias que não sejam condicionados a um único recorte da realidade e que envolvam, além da racionalidade, a sensibilidade dos envolvidos.

Outro ponto a ser destacado em Paulo Freire é a coerência entre o dizer e o ser:

É preciso insistir: este saber necessário ao professor - que ensinar não é transferir conhecimento - não apenas precisa de ser apreendido por ele e pelos educandos nas suas razões de ser - ontológica, política, ética, epistemológica, pedagógica, mas também precisa ser constantemente testemunhado, vivido.

Como professor num curso de formação docente não posso esgotar minha prática discursando sobre a Teoria da não extensão do conhecimento. Não posso apenas falar bonito sobre as razões ontológicas, epistemológicas, políticas da Teoria. O meu discurso sobre a Teoria deve ser exemplo concreto, prático, da teoria. Sua encarnação. Ao falar de construção do conhecimento, criticando a sua extensão, já devo estar envolvido nela, e nela, a construção, estar envolvendo os alunos. (Freire, 1996, p. 52-53). 
Essas considerações apontam para um universo de possibilidades de trabalhos que podem efetivamente contribuir para uma formação mais crítica e sensível de professores, capazes de fazer suas escolhas pautando-se em suas convicções e na realidade escolar.

O caminho proposto pelas autoras deste trabalho e realizado na componente curricular aqui descrita para fomentar a criticidade e a sensibilidade dos professores em formação inicial é a ampliação dos espaços e linguagens para diferentes formas de expressão do pensar e do sentir dos envolvidos.

Deixando um pouco de lado um modelo racional ou cerebral de aprender - que passa pelo tratamento daquilo que é ou pode ser, de alguma forma, palpável ou visível - e considerando aquilo que não o é - ou seja, que se constitui em elementos invisíveis ou sensíveis, que muitas vezes mais afetam o processo que os primeiros -, as docentes formadoras e autoras deste artigo se aventuram por atalhos que adentram a imaginação dos discentes. Trazem à tona, por meio do estímulo às expressividades de seus estudantes, revelações gnosiológicas a respeito das temáticas tratadas e referenciadas nos textos estudados, de forma a contemplar possibilidades de aprendizagem na diversidade, na tentativa de busca de um pensar certo pedagógico.

Pensar certo, em termos críticos, é uma exigência que os momentos do ciclo gnosiológico vão pondo à curiosidade que, tornando-se mais e mais metodicamente rigorosa, transita da ingenuidade para o que venho chamando "curiosidade epistemológica". A curiosidade ingênua, do que resulta indiscutivelmente um certo saber, não importa que metodicamente desrigoroso, é a que caracteriza o senso comum. O saber de pura experiência feito. Pensar certo, do ponto de vista do professor, tanto implica o respeito ao senso comum no processo de sua necessária superação quanto o respeito e o estímulo à capacidade criadora do educando. Implica o compromisso da educadora com a consciência crítica do educando cuja "promoção" da ingenuidade não se faz automaticamente. (Freire, 1996, p. 32-33).

Essa busca do pensar certo proposto por Paulo Freire pode ser abordada tanto do ponto de vista do professor em relação aos saberes de seus alunos quanto do ponto de vista do formador em relação aos saberes dos licenciandos e, também, de cada um dos envolvidos em relação a si mesmo, sejam os licenciandos ou os formadores de professores. Acreditamos que essa dimensão de refletir sobre si próprio e suas concepções, à luz de teorias de referência, é que vai desencadear todo o processo de construção de uma postura docente crítica, reflexiva e sensível. Fazer essa autoanálise, porém, não é algo simples. Hubert Godard (2006), ao falar sobre o trabalho de Lygia Clark com objetos relacionais, lembra que:

[...] frequentemente, a história da percepção vai fazer com que, pouco a pouco, eu não possa mais reinventar os objetos do mundo, minha projeção vá associá-los sempre da mesma maneira. Ou seja, vejo sempre a mesma coisa, sempre através do filtro da minha história. (Godard, 2006, p. 73) 
Para romper esse olhar estático e aparentemente imutável, faz-se necessário olhar a mesma coisa com outros olhos ou sob outro ângulo, ou seja, desnaturalizar o que é tido no mundo como natural (Freire, 1996, 1997).

Ao lembrar que não nos comunicamos apenas pela linguagem falada, mas por muitas outras linguagens que, mesmo sendo culturalmente aprendidas, antecedem a fala e estão corporificadas ou impressas no ser do aprendente, sendo uma forma de comunicação primordial, às vezes principal, as formadoras e autoras deste trabalho se valem de múltiplas linguagens em suas aulas nos cursos de licenciatura em que atuam, na busca da construção de uma relação empática e acolhedora, que possa desencadear a construção do conhecimento pedagógico do futuro professor no âmbito individual em meio ao social, representado pelo coletivo da turma.

A compreensão das temáticas trazidas para a sala de aula e dos textos que delas tratam se revela em diversas linguagens. Traduz-se passando pela imaginação e na produção de imagens mentais que se transformam em imagens visuais, como símbolos, ícones, esquemas, diagramas, mapas, desenhos, poemas, vídeos, filmes ou movimentos que transitam pela mídia corporal, tanto no nível microscópico dos fluxos energéticos e materiais intracelulares como no macroscópico, seja num simples gesto como um piscar de olhos, numa escultura corporal ou em jogos cênicos criados de forma improvisada em grupos ou coletivamente.

Em relação aos jogos cênicos ou teatrais, dos quais as docentes se apropriam em vários momentos do trabalho em sala de aula, o roteiro inicial proposto aos estudantes funciona como uma regra para o "jogo" do encontro pedagógico, um recurso para estabelecer o repertório comum ao grupo e desencadear o processo, um parâmetro que gradativamente se dilui e dá lugar à espontaneidade e à expressão da vontade coletiva. Segundo Koudela (2011, p. 48-49):

[...] A relação autoritária percebe a regra como lei. Na instituição lúdica, a regra pressupõe processo de interação. O sentido de cooperação leva ao declínio do misticismo da regra quando ela não aparece como lei exterior, mas como o resultado de uma decisão livre porque mutuamente consentida. Evidentemente, cooperação e respeito mútuo são formas de equilíbrio ideais, que só se realizam através de conflito e exercício de democracia. O consentimento mútuo, o acordo de grupo determina as possibilidades de variação da regra.

Ainda sobre a proposição de jogos cênicos na formação de professores, podemos destacar a referência que Schön (2000) faz à realização de jogos de encenação como uma maneira eficiente para refletir sobre o conhecimento tácito e proporcionar uma efetiva fronteira entre a improvisação e os momentos da vida que nos surpreendem. Em suas palavras:

Uma dramatização é um jogo improvisado no qual os participantes aprendem a descobrir propriedades de uma situação interpessoal e a refletir-na-ação sobre suas respostas intuitivas a ela. Na improvisação, 
seja ela musical ou dramática, os participantes podem conduzir experimentos imediatos nos quais, tendo-se em vista que a improvisação tende a levar à execução, as fronteiras entre os mundos real e virtual possam tornar-se indefinidas. (Schön, 2000, p. 69).

Assim sendo, na prática relatada neste artigo, os leitores poderão identificar vários momentos em que jogos de dramatização e trabalhos de aquecimento corporal provenientes do campo das artes do corpo são empregados em sala de aula pelas formadoras de professores. O trabalho com esses recursos visa fomentar tanto momentos de tomada de consciência dos estudantes acerca de suas representações sobre os saberes docentes quanto momentos de aprofundamento teórico, em que a discussão de textos selecionados é estimulada por meio de leituras sensíveis.

Entendemos por leitura sensível de um texto aquela que possibilita romper com conservas culturais, permitindo a exploração de diferentes formas de interpretar e expressar essa interpretação entre todos os envolvidos. Cassiano Quilici (2005), quando fala sobre o teatro do silêncio, afirma que:

[...] a linguagem corporal é mais permeável às "pulsões", memórias e experiências pouco acessíveis à consciência. O discurso do corpo pode se estruturar a partir desse terreno movediço, trazendo à tona o que não encontra espaço na lógica linear do discurso verbal. (Quilici, 2005, p. 71)

Fazendo uma transposição do teatro para a situação de leitura de um texto de referencial teórico, procuramos estimular a sensibilidade dos envolvidos a fim de que possam se abrir para uma experimentação desse texto por meio de diversas formas de expressão para além da verbal. Abre-se espaço para o reconhecimento, na formação inicial, da dimensão existencial dos saberes docentes, já identificada nos estudos de Tardif sobre os saberes da experiência na profissão:

[...] um professor 'não pensa somente com a cabeça', mas 'com a vida', com o que foi, com o que viveu, com aquilo que acumulou em termos de experiência de vida, em termos de lastro de certezas. Em suma, ele pensa a partir de sua história de vida não somente intelectual, no sentido rigoroso do termo, mas também emocional, afetivo, pessoal e interpessoal. [...] O professor não é somente 'um sujeito epistêmico' que se coloca diante do mundo numa relação estrita de conhecimento, que 'processa' informações extraídas do 'objeto' (um contexto, uma situação, pessoas, etc.) através do sistema cognitivo [...] [ele é] um 'serno-mundo' [...] Uma pessoa completa com seu corpo, suas emoções, sua linguagem, seu relacionamento com os outros e consigo mesmo [...] (Tardif, 2014, p. 103-104).

A abertura desse espaço visa não somente ao reconhecimento dessa dimensão, mas também ao estímulo a uma postura reflexiva diante dela e de seu peso nas tomadas de decisões do professor acerca do processo de ensino e aprendizagem. Para tanto, além do incentivo ao trabalho com 
formas de expressão diversas e elementos artísticos no curso de formação inicial aqui descrito, também são realizadas rodas de conversa ao longo de todo o processo, como será exposto adiante.

\section{A componente curricular didática}

A didática, como ciência pedagógica, vem desenvolvendo-se teoricamente ao longo da história sob diferentes concepções acerca de seu papel nos processos de ensino-aprendizagem. Nessa trajetória histórica, podem-se destacar, de acordo com Libâneo (2010), ao menos três fases: uma em que predomina uma didática de caráter geral, que remete a Comênio e Herbart; outra em que esse caráter é colocado em questão, dados os avanços no desenvolvimento de didáticas disciplinares, voltadas à abordagem das especificidades epistemológicas de cada área de conhecimento que se deseja ensinar; e uma terceira fase, em que se procura conciliar as duas vertentes anteriores, considerando que, além das especificidades de cada área de conhecimento, existem aspectos de caráter geral que permeiam quaisquer atividades de ensino.

É fundamental destacar o valor das transformações pelas quais a didática passou ao longo de sua trajetória histórica - de um período cujo foco era restrito à técnica dissociada do conteúdo a uma fase de perda de identidade diante das demandas epistemológicas de cada área -, que trouxeram à tona uma necessidade de revisão de seu papel na formação de professores, desencadeando no reconhecimento de seu caráter emancipatório, o qual transcende dicotomias como forma/conteúdo e teoria/ prática em direção à valorização da práxis pedagógica.

Luckesi (2013, p. 27-28) compreende "o educador como um sujeito, que, conjuntamente com outros sujeitos, constrói, em seu agir, um projeto histórico de desenvolvimento do povo que se traduz em um projeto pedagógico". Sua ação pedagógica é ideologizada e necessita de opções teóricas explícitas e conscientes, bem como de paixão e comprometimento. Em síntese, afirma que formar o educador

\footnotetext{
seria criar condições para que o sujeito se prepare filosófica, científica, técnica e afetivamente para o tipo de ação que vai exercer. Para tanto, serão necessárias não só aprendizagens cognitivas sobre os diversos campos de conhecimento que o auxiliem no desempenho do seu papel, mas - especialmente-o desenvolvimento de uma atitude, dialeticamente crítica, sobre o mundo e sua prática educacional. O educador nunca estará definitivamente "pronto", formado, pois que a sua preparação, a sua maturação se faz no dia a dia, na meditação teórica sobre sua prática. (Luckesi, 2013, p. 28-29).
}

Com base nessas considerações, é importante explicar o contexto de realização da componente curricular cujas aulas são analisadas neste artigo. Essa componente é obrigatória para todos os cursos de licenciatura da universidade em que é ministrada e de opção limitada para os demais 
cursos de graduação. Isso possibilita que, em uma mesma sala de aula, encontrem-se estudantes com interesses por áreas de conhecimento diversas e com diferentes imagens sobre a área de educação e a profissão de professor. Essa heterogeneidade, que, num primeiro olhar, poderia ser considerada um obstáculo ao desenvolvimento do conteúdo de uma didática de caráter geral, é tomada pelas docentes como riqueza, uma vez que pode proporcionar a criação de um espaço de convivência fértil para a construção de significados, em que contribuições individuais diversas podem se mesclar ao conhecimento epistemologicamente construído.

Dessa forma, a proposta das docentes na didática como componente curricular enquadra-se dentro da terceira vertente citada por Libâneo (2010), tendo como meta proporcionar elementos para que estudantes de diferentes áreas de conhecimento possam reconhecer suas representações acerca do que é ser professor e refletir sobre os diversos significados da profissão docente ao longo da história, à luz de referenciais teóricos, por meio da criação de espaços em que a afetividade e a colaboração sejam reconhecidas e fomentadas.

É fundamental considerar que a criação desses espaços de afetividade e colaboração envolve trocas entre docente e discentes e depende da construção de vínculos de convivência que incitem a reflexão e a expressividade. Para alcançar esse objetivo, as docentes optam pelo uso de recursos provenientes do universo artístico, como jogos de improvisação teatral, esculturas corporais, música, poesia, dança, imagens, entre outros. O trabalho com tais recursos vem mostrando que estimular a expressividade, verbal e não verbal, entre os estudantes possibilita uma experiência inédita para a construção de conteúdos programáticos nessa componente curricular. O uso do corpo como recurso expressivo não verbal foi a prática mais desafiadora. Porém, ao ser introduzido de forma gradativa e sistemática nas aulas, proporcionou uma perceptível mudança na postura dos estudantes, tornando-os cada vez mais livres para improvisar.

Em todas as aulas, os conteúdos de referência eram discutidos por meio de atividades lúdicas em processo de autogestão dos estudantes, vivências pessoais, sempre com suporte da professora e da mestranda que acompanhava as aulas, uma das autoras deste trabalho. De certo modo, foi possível confrontar visões preconcebidas com novas visões sobre a atuação de um professor. Para alguns temas, era solicitado aos participantes da componente curricular que formulassem reflexões individuais, o que visava aprofundar o processo iniciado em sala.

Consideramos que as práticas artísticas exerceram um combate direto aos diversos dispositivos de controle do corpo e do exercício dos discursos e saberes da sociedade disciplinar, rompendo com a docilidade e criando condições para que cada sujeito expressasse sua individualidade e conquistasse a sua liberdade (Foucault, 2014).

Exemplos de ações realizadas e sua repercussão no comportamento dos estudantes são descritos a seguir. 


\section{Algumas ações}

A docente da componente curricular levava para a sala de aula um címbalo, normalmente utilizado em práticas de meditação, relaxamento, terapias e feng shui, com o intuito de acalmar e concentrar a mente. Era usado na aula para informar o início de uma atividade, na maioria das vezes, para abrir rodas de conversa.

O controle do tempo é um fator disciplinador (Foucault, 2014; Geraldi, 2016). Para todas as atividades, estipulava-se uma previsão de tempo. Mas, na verdade, cada pessoa e também os grupos faziam uso do tempo livremente, dispunham do tempo necessário para articular a apresentação das suas ideias. Assim ocorreu em todos os encontros da componente curricular, todas as aulas tinham um tempo para as trocas de ideias. Algumas para falar sobre a atividade feita em casa, outras para fazer a interpretação das apresentações de cenas e vídeos utilizados. O controle do tempo - que não era exatamente um controle, mas uma solicitação para não desviar do assunto - era feito pelos próprios estudantes. A docente, desde a primeira roda de conversa, escreveu em folhas de sulfite coloridas que circulavam a roda a palavra "foco", e, ora ou outra, alguém levantava a folha dizendo "foco". Nas últimas aulas, em situações conflituosas proporcionadas pelos debates nos seminários, um estudante levantou uma folha qualquer e a imaginação da turma ajudou a entender que se pedia "foco".

Outro exemplo de prática que exerceu um combate aos dispositivos de controle foi o trabalho corporal com a exploração de movimento por meio da música e da dança, ações muito presentes nas dinâmicas corporais utilizadas por artistas antes de entrarem em cena. Em sala de aula, essas práticas eram empregadas em momentos que antecediam atividades de criação propostas sobre textos teóricos, normalmente realizadas em grupos. É importante destacar que tínhamos na sala uma estudante com sistema motor dos membros inferiores parcialmente comprometido, que necessitava de um andador para se locomover e para ficar em pé. Essa estudante relatou que se sentia livre nas atividades corporais propostas. Na sala, as várias vozes diziam que, no último dia de aula, existia uma cumplicidade entre todos os que dividiram situações inusitadas com essas dinâmicas, porque tiveram que trabalhar em equipe com pessoas inicialmente estranhas para produção de encenações. Além do espaço para trocas de ideias nas rodas de conversa, as quais, mesmo divergentes, não afetavam o sentimento de pertencimento e liberdade para se expressar. Isso vai ao encontro da afirmação de Koudela (2011, p. 48) sobre jogos teatrais: "quando um indivíduo percebe que não existe a imposição de modelos ou critérios de julgamento e que o esquema é claro, ele deixa de lado o medo de se expor (subjetivismo) e participa da ação conjunta".

Nesse ponto, é importante ressaltar que o estabelecimento e a manutenção da relação pedagógica é um dos maiores desafios enfrentados pelo professor para que seu papel seja alcançado em sala de aula. A relação pedagógica e a compreensão dos diversos fatores envolvidos 
em sua constituição são temas inerentes ao ensino de didática, e é fundamental que se tenha clareza de que a dissociação forma-conteúdo não tem o menor sentido quando um formador objetiva fomentar uma postura ativa, reflexiva, questionadora e comprometida em seus alunos, futuros professores. Sendo assim, podemos relacionar as observações dos estudantes citadas anteriormente, referentes à cumplicidade construída entre os colegas de turma por meio das atividades corporais, como um importante impacto dessas atividades em seus conhecimentos pedagógicos acerca do que é ser professor, compreendendo a coerência necessária entre o dizer e o ser, falar e agir, conforme proposto por Paulo Freire. Ao afirmar a existência de cumplicidade entre os elementos do grupo, os estudantes estão reconhecendo o caráter coletivo da atividade docente, um dos conteúdos específicos da didática sob uma perspectiva crítica como a indicada por Luckesi (2013, p. 34): "a didática, ao exercer o seu papel específico, deverá apresentar-se como elo tradutor de posicionamentos teóricos em práticas educacionais". Nas aulas da componente curricular aqui analisada, os estudantes tiveram oportunidade de discutir textos teóricos sobre diferentes vertentes de ensino ao longo da trajetória histórica da didática, sendo tais discussões realizadas de forma integrada, em que teorizações sobre a importância da criação de elos entre professor e alunos eram debatidas em situações nas quais esses vínculos se criavam por meio dos jogos teatrais e demais atividades corporais.

Não se pode deixar de considerar que a prática corporal também causou incômodo para alguns, por não se sentirem à vontade em dançar, não gostarem da música utilizada ou ficarem constrangidos por ter que movimentar o corpo, posto que a consideração de uma postura adulta na universidade não comporta ou não condiz com o uso do corpo. Esse desconforto, porém, não foi visto pela docente como impedimento para o trabalho corporal, uma vez que o desenvolvimento da criatividade almejado com tais atividades exige justamente o despertar desses corpos adormecidos.

O trabalho de reflexão atravessado pelo corpo também pôde ser observado em uma atividade que, em princípio, seria extremamente mental, a leitura de um texto de conteúdo factual como Dez novas competências para uma nova profissão, de Perrenoud (2001), prevista na ementa da componente curricular. Para promover uma leitura sensível e crítica, a sala foi dividida em dez grupos, cada qual deveria sortear uma das competências, criar uma escultura corporal e representá-la para a turma, que iria adivinhar a competência correspondente à escultura representada. Essa atividade proporcionou bastante desconcentração e imaginação entre os participantes. Vale salientar que todas as competências foram identificadas pela maioria dos estudantes.

Outra evidência de que o trabalho corporal agiu no combate aos dispositivos de controle foi o aprimoramento das interações entre os participantes nas aulas, que a cada encontro passavam a se conhecer e 
a se reconhecer na figura do outro. Assim, à medida que as aulas foram acontecendo, os grupos foram tornando-se cada vez mais desenvoltos em suas propostas, indicando que estava em andamento um processo de maior amadurecimento e compreensão do trabalho criativo, que deles era esperado, mais próximo do lúdico e do interativo.

Estava implícita, na estruturação das aulas, a necessidade de uma educação para a sensibilidade, para a igualdade, para a aquisição da autonomia, por meio de uma liberdade de ação real ou mesmo pressuposta. E, ainda, estimular o aluno a agir com criatividade, a se exprimir com propriedade, a construir espaços próprios, a tomar iniciativas, a participar com responsabilidade, enfim, a fazer acontecer e a aprender a aprender. (Behrens, 2005 apud Flach; Behrens, 2008).

\section{Expressões dos estudantes}

A componente curricular didática compreende, nessa universidade, um total de 48h, distribuídas em 12 aulas de 4 h cada. Na versão apresentada neste artigo, essas aulas abrangeram quatro grandes blocos temáticos: Ser professor aproximação inicial (memórias e tomada de consciência de saberes e representações dos estudantes, composição/contraposição entre ideias prévias e referenciais teóricos); Ser professor na trajetória histórica da didática; Ser professor, segundo três tendências identificadas historicamente (racional técnico, reflexivo, intelectual crítico); Ser professor diante de questões críticas do ensino (indisciplina, sexualidade, drogas, violência, pluralidade cultural).

A estruturação das aulas nos quatro blocos citados reflete a intenção das docentes de romper com as tradicionais dicotomias forma/conteúdo e teoria/prática, de modo a alcançar uma coerência entre o dizer e o ser, em acordo com as proposições de Freire (1996), que coadunam com a visão de Luckesi acerca do papel da didática na formação do educador: "um modo de auxiliar o sujeito a adquirir uma atitude crítica frente ao mundo de tal forma que o habilite a agir junto a outros seres humanos num processo efetivamente educativo" (Luckesi, 2013, p. 29) e um "elo tradutor de posicionamentos teóricos em práticas educacionais" (Luckesi, 2013, p. 34). Ao assumirem a didática nessa perspectiva, as docentes procuram articular, em suas aulas, elementos subjetivos dos estudantes, presentes em suas memórias e concepções sobre a vida escolar, com conteúdos específicos da didática - como sua trajetória histórica; natureza do trabalho docente e profissionalização; relação pedagógica; teorias sobre ensino e aprendizagem; recursos e modalidades de ensino e avaliação -, por meio do envolvimento dos estudantes em vivências corporais, sensibilizações e uso de diferentes formas de expressão, sempre acompanhados de leituras de referenciais teóricos e rodas de conversa.

Os temas e as expressões dos estudantes discutidos neste artigo correspondem ao bloco inicial de aulas, voltado para a tomada de consciência 
de saberes e representações sobre o ser professor mediante suas memórias da escola e a composição/contraposição entre ideias prévias e teorias. Em todas as aulas aqui consideradas, as atividades propostas conduziam os aprendizes a relacionar os temas específicos com os conhecimentos prévios sobre o assunto e as vivências pessoais. Também proporcionavam a construção de vínculos de convivência.

Logo na primeira aula, por meio de uma dinâmica de livre evocação de palavras, todos falaram suas impressões sobre o que é a didática. Assim, foi construído um conceito com base em um repertório tácito de palavras, no qual as combinações de similaridades criaram três eixos temáticos: afetividade (empatia, palatável, dedicação); conteúdo como conhecimento (compreensão, absorção); e técnico (ferramentas, recursos, métodos).

Para pensar sobre ser professor, foi solicitado que os aprendizes trouxessem lembranças da escola básica e as escrevessem em uma folha verde que lhes foi entregue. As lembranças estavam permeadas por cores, sensações, sabores e sons. São exemplos de fragmentos dessas lembranças:

Quando me lembro do tempo da escola vejo imagens das paredes cor de abacate e uma pintura da Magali comendo melancia e em outra parede [...].

Lembro-me muito que eu odiava as paredes cinzas daquela escola [...].

Lembro-me da professora de português. Ela era uma das únicas que conseguia controlar o barulho da classe.

Consigo recordar com bastante clareza sua voz doce, sua simpatia [...].

Várias lembranças se referiram, nas palavras dos próprios estudantes, à parte humana do professor e do aluno, que remete aos sentimentos, à amizade, ao respeito, ao cuidado, ao incentivo. Vale destacar que essa dimensão humana da relação pedagógica é reconhecida como exceção nestes depoimentos:

O professor que me mostrou que ser professor é muito mais que passar lição em aula e para casa. A parte humana do aluno, para ele, era muito importante $[\ldots]$.

Entretanto, tal professora, diferentemente de diversos outros que tive, gostava muito do que fazia e transmitia tal sentimento aos alunos. Estava sempre disposta a ajudar e preocupada com os alunos, trazendo seu lado humano para a sala.

Me recordo de uma professora que percebeu o meu desinteresse, falta de atenção, devido a necessidade de utilizar óculos.

Na segunda aula, com o intento de aprofundar essas lembranças, foi pedido que cada estudante escrevesse uma carta para o professor citado em sua memória, escrita na aula anterior, agradecendo, desabafando. A intenção da docente era que os estudantes identificassem, nos professores por eles mencionados, posturas ou condutas desejáveis 
ou não desejáveis para ser professor. A apresentação das produções para toda a turma possibilitou a identificação de três tipos de condutas: as estritamente desejáveis, as estritamente não desejáveis e aquelas que geravam dúvidas quanto à sua inserção nas categorias anteriores. Com essa divisão, foram constituídos três grupos de estudantes, aos quais foi solicitado que criassem uma cena teatral para representar um professor e sua conduta, de acordo com a classificação realizada. Esse processo de criação resultou em um dado interessante: as três representações traziam a cena de um professor com condutas não desejáveis. Essa aparente coincidência é um elemento indicativo do quanto condutas docentes não desejáveis podem ser marcantes na vida dos alunos: professores autoritários, com atitudes coercitivas, displicentes em relação ao planejamento das aulas, mas exigentes em relação à quantidade de exercícios, apenas preocupados com o conteúdo.

Após o trabalho com as memórias dos estudantes e suas concepções sobre o ser professor, que trouxeram à tona a dimensão humana da docência, a terceira e a quarta aulas foram dedicadas à discussão de textos de referência acerca da dimensão política da profissão docente. A finalidade nessas aulas era proporcionar um espaço para que os estudantes pudessem compor/contrapor suas representações com os referenciais teóricos da área.

No período de uma semana entre a segunda e a terceira aulas, como tarefa extraclasse, com base na leitura do texto de referência "O papel da didática na formação do educador" (Luckesi, 2013), os estudantes deveriam escrever suas impressões sobre as ideias nele contidas, selecionar um excerto representativo dessas ideias e uma imagem de escola que se relacionasse ao assunto (Quadro 1).

Luckesi foi um autor importante para a turma de didática, pois foi o primeiro apresentado, mas, sobretudo, porque traz uma visão engajada politicamente sobre a atuação de professores; fazendo com que os estudantes revissem seus pensamentos sobre a esfera que abrange essa profissão, discutindo o ser professor imbricado no ser aluno, uma vez que as histórias de professores são histórias de alunos que se fizeram professores.

A terceira aula foi dividida em dois momentos: um de sensibilização e outro de compartilhamento das produções dos estudantes (roda de conversa). A sensibilização foi proposta por meio de uma atividade corporal, compreendendo controle da respiração, acompanhado de comandos de relaxamento de partes do corpo. O grupo foi preparado para ouvir a canção "Coração de estudante", de autoria de Wagner Tiso e Milton Nascimento. Em seguida, a pedido da docente, uma estudante leu o poema "A escola", de Paulo Freire.

No segundo momento, roda de conversa, cada estudante apresentou sua imagem do texto e explicou sua compreensão a respeito, enquanto a docente registrava as principais ideias na lousa. O Quadro 1 apresenta a descrição da expressão das ideias de um dos estudantes, que foi exposta e discutida em roda de conversa. 


\title{
Quadro 1 - Registro de Estudante para a Atividade Extraclasse Discutida na Terceira Aula
}

\begin{abstract}
Impressões sobre as ideias contidas no texto - A necessidade de colocar escolas de ensino básico e médio nos primeiros lugares dos diversos rankings da educação, na maioria das vezes, deixa o ensino maçante e desagradável. As diversas metodologias de ensino, na maioria das vezes, não consideram a satisfação do aluno no aprendizado, mas sim números que medem o "resultado" da escola. Estamos transformando a escola em adestramento de crianças, que aprendem a escrever, contar e decorar.

Excerto representativo dessas ideias - "Daí a ansiedade, hoje existente nos meios educacionais, por receitas e mais receitas de "como fazer" a educação, na expectativa de sabendo-se como fazer se chegará a algum resultado". (Luckesi, 2013, p. 33)

Imagem de escola relacionada ao assunto - A imagem* em preto e branco selecionada pelo estudante remete a uma situação de macroavaliação, em que estudantes aparecem sentados em carteiras organizadas em fileiras, todos de cabeça baixa, escrevendo e sendo supervisionados.
\end{abstract}

Fonte: Registro de estudante.

* A imagem selecionada pelo estudante foi omitida e substituída por uma descrição por não ter a fonte especificada.

A crítica do estudante ao sistema de ensino das pedagogias hegemônicas está inteiramente de acordo com a sociedade capitalista contemporânea. A transmissão do conhecimento é um modelo de ensino reprodutivo, é autoritária, impositiva e repressiva, porque entende os processos educacionais centrados no professor, o que torna a relação pedagógica hierarquizada, sendo este mais importante que o estudante, o qual deve seguir atentamente a exposição e é visto como um ser receptivo e passivo. Assim, a disciplina é a forma de garantir a atenção, o silêncio e a ordem (Veiga, 2010) e o principal objetivo são os resultados.

Na quarta aula, a sala foi dividida em dez grupos e cada um leu uma das cartas do livro Professora sim, tia não: cartas a quem ousa ensinar, de Paulo Freire, objetivando identificar os ensinamentos contidos na carta; relacioná-los às boas práticas de um professor, já apontadas em aulas anteriores; e acrescentar outras, indicadas pelo autor, exemplificando-as com excertos do texto lido. Essa produção deveria ser organizada pelos grupos na forma de uma apresentação para a turma, com o uso de slides e algum recurso artístico: vídeo, imagem, cena, poema, música, entre outros. Essa proposta tinha a intenção de estimular os estudantes à exploração de recursos e modalidades didáticas diferentes daquelas já conhecidas e vivenciadas em suas trajetórias escolares, sem deixar de considerar a importância da aula expositiva.

A contraposição entre as cartas produzidas pelos próprios estudantes, dirigidas a professores presentes em suas memórias, e as cartas de Paulo Freire a quem ousa ensinar possibilitou, nas rodas de conversa e nas produções, a construção de um olhar aguçado acerca do tema ser professor. 
Quando se pergunta sobre como o professor deve ser, não podemos nos eximir de questionar o professor formador desses professores: seus valores e suas práticas em relação aos conteúdos conceituais que propaga. Nesse ponto, vamos resgatar aqui o programa dessa primeira fase da componente curricular, voltada a tocar em cada indivíduo e trazer à tona suas lembranças para trabalhá-las em dois aspectos: criação de critérios de valores sobre a atuação do professor, já que todos foram um dia estudantes, e ampliação da visão sobre atuação do professor para a esfera social. Foi possível verificar nesse processo uma coerência entre as teorias abordadas, os autores de referência da componente curricular e a metodologia de ensino adotada pela docente da turma, que valorizava e acolhia, em cada atividade realizada, as sensibilidades: as lembranças da escola, incluindo histórias da própria docente, as imagens e associações com imagens, os roteiros para cenas e o compartilhamento de lembranças.

\section{Considerações finais}

Retomando a ideia deste artigo, os caminhos de formação trilhados ao longo das aulas descritas nos trouxeram evidências de que a proposição de vivências corporais, sensibilizações e uso de diferentes formas de expressão favoreceu a criação de vínculos entre estudantes e docente. Esses vínculos foram fundamentais para a construção de uma relação pedagógica em que ações voltadas para a tomada de consciência dos estudantes acerca de seus repertórios sobre os temas discutidos, assim como sua ampliação à luz de teorias, desenrolassem-se em coerência com os referenciais teóricos adotados. Vale destacar, mais uma vez, as palavras de Luckesi (2013, p. 29): "o ideal seria que educador e educando, conjuntamente, conseguissem, atuando praticamente no e com o mundo e meditando sobre essa prática, desenvolver tanto conhecimentos sobre a realidade como atitudes críticas frente a mesma".

O alcance dessa coerência entre dizer e ser, na visão das autoras deste texto, está diretamente relacionado ao trabalho com atividades corporais, que proporcionavam, além do relaxamento de tensões e criação de vínculos, a ampliação de formas de significação. Essas significações, porém, não seriam bem aproveitadas caso não fossem acompanhadas de rodas de conversa, nas quais participantes podiam expor suas interpretações do que era feito, buscar articulações com textos de referência dos temas em estudo e relatar como se sentiam em relação às proposições da docente e às interações estabelecidas com o grupo. A ênfase nos momentos de aquecimento do grupo, no início de cada aula, e nos de compartilhamento de ideias e sensações, ao final, sempre intercalados com discussões de textos que traziam o conteúdo formal contemplado na componente curricular, proporcionou a criação de uma ambiência em que afetivo e cognitivo puderam ser observados e reconhecidos como parte do processo de vir a ser professor.

Invocar o mundo sensível na educação é propor ações que se configurem numa experiência, que ensejem novos modos de sentir e que 
induzam a produção de nova estética para o processo educativo. Uma maneira de preparar um mundo a ser construído e pensar numa forma para esse novo mundo.

Existem nas artes vários modos de dizer fazendo, como a pintura, a música, a dança, entre outras, chamados por Racière (2009) de partilha do sensível, quando num espaço tais atividades são compartilhadas. No caso das aulas da componente curricular didática, as rodas de conversa, que se seguiram a cada atividade envolvendo elementos artísticos articulados a conteúdos específicos presentes em textos lidos pelos estudantes, mostraram-se espaços privilegiados para essa partilha. Atuar como um professor sensível é abrir e sustentar um espaço de circulação a novas associações de energia, ideias e vontades, a formas invisíveis e imprevisíveis de ser, estar e perceber o mundo. Uma atuação sensível abre outros campos do possível, criando condições à inteligibilidade do sentir. Foi assim que observamos, nos dados aqui apresentados, uma alteração na forma de uso dos dispositivos de controle do tempo - címbalo - e do foco das discussões - folha de papel com a inscrição "foco" -, que passaram de instrumentos externos, a princípio introduzidos pela docente, a instrumentos integrados ao grupo, usados de forma afetiva, efetiva e harmoniosa por qualquer um de seus componentes ao longo das discussões. Desse modo, a responsabilidade de condução das aulas foi, aos poucos, descentralizando-se da figura da docente e sendo assumida por todo o grupo ali reunido.

Assim como o uso de instrumentos externos passou por transformações ao longo das interações que constituíram o grupo docente-estudantes, o uso dos corpos também se transformou nesse processo. Se, a princípio, o estranhamento dos estudantes em relação à realização de aquecimentos corporais em uma aula de didática foi elevado, à medida que as aulas foram transcorrendo, foi sendo reduzido, dando espaço à criação de vínculos afetivos, que possibilitaram o rompimento com dispositivos de controle corporal. Os estudantes, que chegaram às aulas dessa componente curricular acostumados a uma atitude corporal passiva de permanecerem sentados e calados diante do professor, passaram a reconhecer seus corpos como parte da expressão de suas ideias e, assim, parte de seus processos de reflexão acerca dos temas discutidos em aula.

As vivências apresentadas e analisadas possibilitaram interações que levaram ao desenvolvimento de um respeito mútuo extremamente fértil para a promoção da criatividade e propiciaram, assim, uma educação para a autonomia, ainda que limitada ao contexto das relações nessas aulas. Tanto criatividade quanto autonomia foram notoriamente evidenciadas nas diversas produções dos estudantes ao longo de todo o período em que se desenvolveu a componente curricular, compreendendo atuações dos futuros professores voltadas para o vislumbramento de novas possibilidades de interpretação e ação nos processos educativos.

Com isso, consideramos que o trabalho executado na componente curricular proporcionou uma ressignificação de instrumentos envolvidos na discussão de teorias. O que reforça nossa proposição de uma formação de professores impregnada por elementos sensíveis, que possibilitem ampliar repertórios de representações sobre a atuação profissional e 
reconhecer o corpo não apenas como suporte, mas elemento constituinte da subjetividade, construída por meio de uma ligação entre todos os aspectos humanos - percepções, sensações, sentimentos, intuições, criações, crenças, preferências, paixões, espiritualidade e razão. Sendo assim, dado que as diversas interpretações e assimilações de um objeto compreendem um processo de integração do sujeito em toda a sua complexidade, a sensibilidade deve ser considerada no processo de constituição do ser professor.

\section{Referências bibliográficas}

ALARCÃO, I. Professores reflexivos em uma escola reflexiva. 8. ed. São Paulo: Cortez, 2011.

ANDRÉ, M.; CRUZ, G. B. A produção do conhecimento didático na Rbep (1998-2010). Revista Brasileira de Estudos Pedagógicos, Brasília, v. 93, n. 2, p. 443-462, maio/ago. 2012.

CONTRERAS, J. A autonomia de professores. 2. ed. São Paulo: Cortez, 2012 .

FLACH, C. R. C.; BEHRENS, M. A. Paradigmas educacionais e sua influência na prática pedagógica. In: CONGRESSO NACIONAL DE EDUCAÇÃO, 8., 2008, Curitiba; CONGRESSO IBERO-AMERICANO SOBRE VIOLENCIAS NA ESCOLA, 3., 2008, Curitiba. Anais... Curitiba: PUCPR, 2008.

FOUCAULT, M. Vigiar e punir: nascimento da prisão. 40. ed. Rio de Janeiro: Vozes, 2014.

FREIRE, P. Pedagogia da autonomia: saberes necessários à prática educativa. 15. ed. São Paulo: Paz e Terra, 1996.

FREIRE, P. Professora sim, tia, não: cartas a quem ousa ensinar. São Paulo: Olho d’Água, 1997.

GERALDI, J. W. Professor: construção e reconstrução da identidade profissional. 2016. Disponível em: <htttp://portos.in2web.com.br/passagensblogdogeraldi/159-professor-construcao-e-reconstrucao-da-identidadeprofissional>. Acesso em: 23 maio 2016.

GODARD, H. Olhar cego: entrevista com Hubert Godard, por Suely Rolnik. In: GODARD, H. Lygia Clark: da obra ao acontecimento. São Paulo: Pinacoteca do Estado, 2006. p. 73-79. 
KOUDELA, I. D. Jogos teatrais. São Paulo: Perspectiva, 2011.

LIBÂNEO, J. C. Integração entre didática e epistemologia das disciplinas: uma via para a renovação dos conteúdos da didática. In: DALBEN, A. et al. (Orgs.). Convergências e tensões no campo da formação e do trabalho docente: didática, formação de professores, trabalho docente. Belo Horizonte: Autêntica, 2010. p. 82-105.

LUCKESI, C. O papel da didática na formação do educador. In: CANDAU, V. M. (Org.). A didática em questão. 34. ed. Petrópolis: Vozes, 2013. p. 25-34.

NÓVOA, A. Os professores e as histórias de sua vida. In: NÓVOA, A. (Org.). Vidas de professores. Porto: Porto Editora, 1992. p. 11-30.

PERRENOUD, P. Formar professores em contextos sociais em mudança: prática reflexiva e participação crítica. Revista Brasileira de Educação, Campinas, n. 12, p. 5-21, set./dez. 1999.

PERRENOUD, P. Dez novas competências para uma nova profissão. Pátio: Revista Pedagógica, Porto Alegre, n. 17, p. 8-12, maio/jul. 2001.

PIMENTA, S. G. Professor pesquisador: mitos e possibilidades. Revista Contrapontos, Itajaí, v. 5, n. 1, p. 9-22, jan./abr. 2005.

QUILICI, C. S. Teatros do silêncio. Sala preta, São Paulo, v. 5, p. 69-80, 2005.

RACIÈRE, J. A partilha do sensível: estética e política. São Paulo: Editora 34, 2009.

SCHÖ, D. A. Educando o profissional reflexivo: um novo design para o ensino e a aprendizagem. Porto Alegre: Artmed, 2000.

TARDIF, M. Saberes docentes e formação profissional. 17. ed. Petrópolis: Vozes, 2014.

VEIGA, I. P.A. Didática: uma retrospectiva histórica. In: VEIGA, I. P.A. (Coord.) Repensando a didática. 22. ed. Campinas: Papirus, 2010. p. 25-40.

Recebido em 18 de agosto de 2016.

Solicitação de correções em 20 de março de 2017.

Aprovado em 3 de maio de 2017. 